\title{
Environmental Education in Singapore: A Curriculum for the Environment or in the National Interest?
}

\author{
Francis Wong Bing Kwan \\ Principal, Shung Tak Catholic Secondary School, Yuen Long, Hong Kong
}

\author{
Philip Stimpson \\ Senior Lecturer, Faculty of Education, The University of Hong Kong, Hong \\ Kong
}

Over the last decade, Singapore, in line with other countries in the region, has been attempting to develop a cross-curricular environmental education programme. This paper examines the context variables that have helped to shape the environmental curriculum in schools using evidence from interviews conducted with key players and teachers involved in the development. Despite a rhetoric couched in progressive terms focusing on 'awareness', 'attitudes', 'action', 'participation', 'experience' and 'life-long learning', the curriculum detail stresses information of a dominantly scientific nature reflecting a largely academic rationalist, rather than socially critical, approach. The interviews revealed three underlying themes that help to explain the sort of curriculum that is found: (1) a pragmatic utilitarian concern for the urban environment of Singapore; (2) a school and examination system that is still largely focused towards traditional disciplinary knowledge; and (3) the overriding influence of government and the balance that it prioritises between environment, economic development, social stability, nation building and external image.

Keywords: Environmental education, Singapore, curriculum

\section{Introduction}

Environmental education is a global concern developed in a time of social, economic and ecological globalisation. While environmental education programmes around the world share common aims based broadly on ideas from various UNESCO conferences over the last 25 years, they often differ in focus as a consequence of the environmental, historical, sociopolitical and educational systems in which they develop. This paper is concerned with environmental education in Singapore and the context variables that have shaped its character over the last decade. The focus is concerned with the influence that society in its various aspects exerts on the formation of the environmental education curriculum.

Environmental curricula, like any other, are social constructs (Print, 1993). They are artefacts that are an extension of society, culture (Reynolds \& Skilbeck, 1976) and of the economic and physical conditions. They represent a forum in which a variety of interest groups within a society compete to promote their conceptions of valid knowledge (Goodson, 1994). In complex societies, decisions about worthwhile knowledge will reflect competing forces and perceptions of 
what is and what is not central. Marsh and Willis (1995) argue that there are three focal points around which decisions about a curriculum are made. The first focuses on the nature of the subject, namely in the context of this paper the environment, and on choices about what to emphasise and what to omit and about what is important and what is not. The second focal point concerns the nature of the society for, if knowledge and awareness is to have value, environmental education must lead the student not only to a knowledge of the world for its own sake but also to an understanding that can be applied in the world. The nature of the social, political and economic system needs to be taken into account. The third focal point centres on the nature of the individual and the individual's needs. The curriculum is thus a negotiation in which these three foci interplay. However, it is arguably the second concerned with society and its perceptions, beliefs and desires to either reproduce and perpetuate themselves or change that is the most crucial. Curricula may reflect society or they may lead to change (Print, 1993). As environmental educators develop the curriculum, they, conditioned by their lived worlds and awarenesses, translate their assumptions, ideas, understandings, values and attitudes into curriculum aims, foci, objectives, content and pedagogy. It is not possible to talk about context-free environmental education curricula. It is the situatedness that defines what is valid knowledge.

Valid knowledge in environmental education terms takes various forms and a number of workers (see e.g. Kellert, 1997; Robertson \& Krugly-Smolska, 1997) have attempted to define variants. Robertson and Krugly-Smolska (1997), in a review of different conceptions of environmental education in the literature, differentiated six views or perspectives taken in environmental education curricula: (1) utilitarian; (2) aesthetic; (3) ecological; (4) ethical; (5) deep ecological, or Gaian, in a combination of (3) and (4); and (6) the socially critical. It could be argued that these are more properly dimensions in that more than one is likely to be present in any situation. Nevertheless, these different conceptions offer a useful platform for analysing and classifying the focus of environmental education in Singapore because each conception reflects in part different social concerns.

The paper is concerned with curriculum presage or those forces and activities that mould the curriculum. It is in three parts. The first, as essential background, outlines the nature of environmental education in Singapore. The second describes the methods used in the study. The third and major part of the paper provides an analysis of interview and documentary data that led to identification of key themes in the environmental curriculum history of environmental education in Singapore.

\section{Environmental Education in Singapore}

Singapore, with a population of about four million and the third highest GDP per capita in Asia (US\$22,748 in 2001; http:/ / www.singstat,gov.sg/keystats / annual/indicators, 2003), styles itself as the 'Garden City of the Tropics' (Ministry of Environment, 1993). Since independence in 1965, its Government has been ambitiously proactive in economic terms. Economic development has led to rapid urbanisation of the island city-state with resultant loss of natural ecosystems and increasing pollution (Koh, 1993). The environmental challenges are in essence largely (but not solely) urban problems. 
As a gesture to show the Government's concern for the environment, a Ministry of Environment was established in 1975 as one of the first of its kind in Asia to tackle many of these problems. One element in its armory is education.

Environmental education is a direction of the Green Plan [the environmental protection policy for Singapore- authors]. Cultivating knowledge of the scientific and social significance of the environment is the first step in the founding of an environmentally friendly society. It is through knowledge and awareness that positive values and attitudes emerge, values and attitudes that will prompt action to make the adjustments to lifestyles and consumption habits that will reduce the burden we place on the environment. (Ministry of Environment, 1993: 13)

The Ministry of Environment, which sees its mandate as being in the field of environmental protection and public health and which as we will see is a key player, defines environmental education in Singapore as incorporating:

all aspects of the environment, natural and man-made, with emphasis on our physical and health environment. It includes all activities involving man as a producer as well as a consumer of goods. Environmental education should be a life-long process, whether at home, in school or at work and community places. (Ministry of Environment, 1993: 3)

The Ministry of Education writes the programme for environmental education in schools, although this is based on environmental issues initially identified by the Ministry of Environment. Teaching and learning processes are the main concern of the former while the latter is more concerned with content. The approach in the formal school sector broadly follows views expressed at various UNESCO conferences to integrate environmental education into the curriculum through infusion into existing school disciplines and areas of study (UNESCO, 1978; UNESCO-UNEP, 1988). As in many other educational systems, this is primarily through geography and through biology in secondary schools and through social studies in primary schools (Lim, 1992). In addition, extracurricular activities act as an important medium and schools are encouraged to involve themselves in one of six programmes from the Public Education Department within the Ministry of Environment such as 'The Seashore Life Programme' and 'The Clean and Green Week Campaign'.

The overall intention is that environmental education should emphasise action, active pupil involvement and experiential learning. The emphasis can be identified in the aims of environmental education for Singapore. These are seen as going beyond school into the community and are apparent in the following quotation from official documents from the Ministry of Environment.

The overall goal of environmental education is to cultivate amongst the population an awareness and understanding of the environment and to encourage them to take an active role in the protection and maintenance of the environment. 'Awareness' and 'Action' would therefore be the twin guiding principles of environmental education in Singapore. (Ministry of Environment, 1993: 4) 
To build an environmentally proactive society, new directions were necessary. The Clean and Green Campaign in 1990 was the first public education campaign in the new approach of the Singapore Green Plan. The approach is to build environmental consciousness based on the following: consciously integrating environmental education into the formal education system, educating through participation and fun rather than compulsion and fines, involvement of and leadership by environmentally committed organisations and business rather than just the government, and concentrating on broad based campaign themes that would be coherently developed over the years rather than ad hoc themes to meet the need of the day ... The action programmes that will be carried out aim to make environmental education a lifelong process. There will be a properly structured system to impart information and values on the environment to the individual through his developing years to adulthood. (Ministry of Environment, 1993: 13-14)

However, in the statement of outcomes of education from the Ministry of Education (Ministry of Education, 2000a) there is no direct reference to environmental education, although there is the aim for students 'to become committed to improving society' which presumably includes the environment. While the environment is not listed, among the eight intended outcomes for secondary schools, the fourth is to be enterprising and innovative and the eighth is to know and believe in Singapore, indicative perhaps of the relative importance of environment, economy and nation.

Overall, environmental education is viewed as functioning at three levels in schools:

The approach to environmental education in schools is progressive, with the aims of acquiring knowledge, values and action. It can be categorised under three levels, namely, (a) Level I: knowledge, (b) Level II: values, (c) Level III: action. (Curriculum Planning Division, 1993: 25)

There is the implicit assumption that knowledge will lead to appropriate values and hence to action.

Key words in both the thinking of the Ministry of Environment and the Curriculum Planning Division of the Ministry of Education seem to be: 'environmental consciousness', 'knowledge', 'information and values on the environment', 'integration into the formal education system', 'programme coherence', 'participation', 'action' and 'lifelong process'. To this list must be added: 'scientific perspective'. While infusion into the whole school curriculum is implied, other statements emphasise a focus largely within science teaching.

By the end of primary education, all children will have been taught through the science subject common to all streams, a basic appreciation of the natural environment and its ecological foundations and basic concepts of the management of natural resources and causes of pollution. (Curriculum Planning Division, 1993: 26)

This is also apparent at secondary level where concern for the environment is largely expressed in the syllabi for environmental science and geography 
(Ministry of Education, 2000b). In the former, the focus is on habitat, energy transfer systems within ecosystems, nutrient cycles and man's impact on the ecosystem and, in the latter, on physical systems, pollution and methods of conservation (Boh, 1991; UNESCO, 1990).

To sum up, the approach seems to comprise a combination of the utilitarian, the ecological and the ethical with the first tending to dominate and the last possible as a servant of the first, but these issues will be discussed later in the findings.

\section{The Study}

The aim of the study was to uncover elements in the curriculum context of Singapore that have shaped environmental education and defined its character. A grounded theory methodology (Glaser \& Strauss, 1968) was adopted within an overall ethnographic approach. Whilst there are official curriculum statements of intentions in Singapore with respect to environmental education, little if any empirical evidence exists on the underlying focus of environmental education in the country and on forces at work. For this reason, a grounded approach, building generalisation out of observation, seemed the direction to take. Curriculum development is in practice highly complex. Some determinants are readily observable but others only become apparent through close day-to-day contact with curriculum developers in a way akin to ethnographic study. One of the researchers periodically visited Singapore over four years (1994-8) becoming part of the curriculum development scene in environmental education, interviewing participants in environmental education and collecting documentary evidence such as government reports and papers by local academics. This researcher sought to become immersed in the concerns of people involved in developing and teaching environmental education. Much of the research was involved with locating central figures, building rapport, watching, listening and learning. The aim was to uncover the factors that the environmental workers in Singapore saw as determining what went on and to provide descriptive accounts.

The intention was to work informally in the system but teachers would not respond to unauthorised requests. Once, however, contact had been made with the Ministry of Education and approval gained, access opened up and research proceeded smoothly. Interviews did not seem constrained by the need to gain prior approval and the interviews proceeded freely. All interviews represent a filtered expression of opinion but the people interviewed did not seem to be any more or less restrained in expressing their views than in any Western society. Clearly government officials spoke as civil servants but teachers spoke as concerned educators rather than following any prescribed line. Interviews, both person-to-person and small group, were conducted with four government officials, one NGO spokesperson, 40 teachers and three tertiary teachers. These interviews were tape-recorded. In addition, field notes were made during or immediately after meetings in which key comments were recalled. The taperecorded interviews were transcribed and read numerous times to illicit key ideas that could then be triangulated and tested in subsequent interviews. By this process of constant comparison, conceptual categories representing ideas about 
the determinants of environmental education in Singapore were defined and key themes identified.

\section{Findings}

From the interview and documentary data, there emerged three themes that, it is argued, help to explain the particular form that environmental education has taken in Singapore. These are:

- A pragmatic utilitarian concern for the urban environment of Singapore;

- The influence of the education system;

- The strong hand of government in the development of environmental education.

\section{A pragmatic utilitarian concern for the urban environment of Singapore}

The Singaporean Government's concern for the environment and for development of the city-state cannot be separated and is a source of the early focus on environmental health that continues to the present day. Often it has been that latter which has been the driving force in environmental initiatives. Lee Kwan-yew, the former Prime Minister, stated, 'If you put people in a good environment, you get people that are healthy and industrious, and they can work and think' (cited in Savage \& Lau, 1993: 65). This remains a current view.

As Singapore has progressed, increasing population has added to urbanisation and hence (to stress) the physical environment. Singapore is thus characterised, as in Hong Kong, by its man-made environment with the maintenance of people's good health as a major policy. (Ministry of Environment Official J)

An environmental educator working in a university concurred in an interview.

If our people have good health, the Government's expenditure on medical services will be less and we will have a better economy. (Educator S)

In a perspective that is supported generally today, early moves into environmental education represent pragmatic responses to the impact of environmental deterioration on the people as creators and builders of the city-state rather than from any general ethical, or deep-ecological, concern with nature and conservation. Thus Koh (1990) comments, on the one hand that:

the tremendous development which Singapore has experienced during the last 25 years has reduced the extent of our [meaning Singaporean] natural habitats. For example, there are now less than 100 hectares of primary forest in Singapore and the 600 hectares of mangrove forest left represent less than $1 \%$ of the original area. The loss of primary forests, mangrove forest and coral reefs has threatened the survival of the flora and fauna that inhabit these habitats. (p. 5)

and the Singapore Branch of the Malayan Nature Society (1990) similarly noted that: 
medical advances have permitted a population explosion which has led to hitherto unparalleled pressure on natural habitats from ind ustrial development, agriculture and urbanisation. Singapore's natural areas have been radically altered through this kind of pressure. (p. 3)

On the other hand, an official from the Ministry of Environment noted that:

our emphasis is very urban. We tackle urban kinds of problems like the breeding of mosquitoes. We are concerned with urban kinds of situation like waste recycling - less about nature conservation and erosion. (Ministry of Environment Official J)

The focus on urban environmental problems was emphasised again later in the interview alongside a utilitarian rather than an ecological or ethical position.

As I mentioned earlier, nature conservation is not the main concern of our Ministry [of Environment]. So, in that sense we [the Ministry of Environment and the Malayan Nature Society] do not come together.

Given, as will be shown later, the important role of this ministry in the development of the formal environmental education curriculum for schools, such differences in philosophical position are crucial.

The concern of the Ministry of Environment, particularly in the early days, was with environmental health and a reflection of Lee Kwan-yew's vision and mission for Singapore. The ministry official quoted earlier noted:

right from the early stages, in the '50s and '60s, we have many diseases in Singapore and Malaysia. We had cholera, typhoid, etc. But all of these diseases are being eradicated... [although] in the last few years, new cases are coming up.

Environmental health continues to be a major element in public concern for the environment. A teacher $(\mathrm{N})$ remarked:

Under British rule, even after the [Second World] War, the cleanliness of Singapore was not that good. That affected people's health. For example, China Town was dirty [and there were] a lot of people staying there. Basically for the benefit of people, we must have a clean environment. On top of this it gives a very good image of Singapore [to the world outside].

Image is another central element in the pragmatic environmental message in Singapore. Kong (1993) noted the importance of neo-utopian slogans such as 'Garden of the Orient', 'Clean and Green Garden City' , 'Tropical City' and 'Environmental City' to planning since independence in 1965 and particularly since the late 1980s with the rise of tourism globally and in Asia in particular. Such slogans have significance for environmental health and tourism (Savage, 1994) but also in attracting hi-tech and service industries to the city-state. Practice is more pragmatic and utilitarian. It is typified by the annual 'Clean and Green Week' that has taken place since 1990. The purpose of such propaganda events put on by the Ministry of Environment is to arouse people's awareness of the environment, maintain a healthy, clean image and attract development. Environment is, to a degree, treated as the servant of development in some quarters. 
Despite this focus on local needs, the global environmental movement in the post Rio/Bruntland era has not been without effect in Singapore. A teacher (L) commented:

In the late 1980s, I felt it [a more global perspective] because I myself became more aware . . It was about five or six years ago [in about 1990], there started a very strong drive in this area. The public became concerned about the environment because it stemmed from other [global] issues such as environmental depletion. It is a great concern for every nation.

This more recent tension between broader global environmentalism and a focus on the environmental needs of Singapore was also recognisable in a conversation with an official from the Ministry of Environment who was talking about the work of government in environmental education. His opening position was that government's involvement was:

mainly in education about public health issues, something about fever, toilets, keeping the place and the environment clean, anti-littering issues. These are closest to the Government in terms of a clean environment and were the main concerns ... [But there is change.] Later on, with the development of UNEP work, environmental concerns are felt all over the world with rising concern about ozone depletion and global warming. Gradually we came to realise that [global] environmental topics are equally important [as local issues]. (Ministry of Environment Official T)

Thus, while a pragmatic utilitarian stance comes over strongly with a concern for solving Singapore's immediate environmental problems, there is growing realisation of wider responsibilities, the need for global as well as local awareness and the need for a deeper ecological position. To what extent, however, this reflects a repositioning as Singapore has become a world economic force and how much it has marked a shift in environmental belief is debatable. Probably there are elements of both but local/domestic issues of concern to the administration of the day seem to dominate.

\section{The influence of the education and school system}

As noted in the earlier section on the nature of environmental education in Singapore, the approach is to infuse environmental topics into existing subjects. A secondary school science teacher described the actual practice in the following way.

For S3 and S4, the scheme of work will be based on the GCE O Level examination syllabus. There is a module within it. In S1, there is a chapter on 'Gases of the Air' and students study air pollution. They have a booklet containing the curriculum. The worksheets suggest [how they can] analyse air from different parts of the city - which parts are more dusty. In S2, when they are studying ecology, there is the whole thing about man's activities that are destroying the environment; there are suggested activities too... In S3 and S4 there is ecology. There [at this level] you get the GCE syllabus with how man's activities upset the balance in nature, it is very much structured into the syllabi. (Teacher J) 
Three messages seem to come through. These are with regard to, firstly, the curriculum and texts, secondly, the examinations, and thirdly, the school curriculum. Curricula are there to be followed and teachers follow the textbooks that put the intended curriculum into practice. The set texts seem to dominate the classrooms not only in what is taught but how it is taught. This is not necessarily a bad thing but, as one teacher commented, the selection of environmental issues in the textbooks are somewhat narrow reflecting to a large extent the immediate concerns of the Singapore environment and the policy initiatives of the Government. This teacher clearly bemoaned what he saw as the inflexibility of curricula. Part of this comes from the curriculum itself but the washback effect of public examinations is also an important factor.

The implemented curriculum in schools in senior forms is strongly examination oriented. The pragmatism described in the previous section penetrates through into the classroom although in a different way. A teacher alluded to this, commenting on the changes that were needed:

If I had complete control of the examination system and so on, I might think about that [implementing change]. The Ministry of Education has no intention to change the syllabus. It is outside my ability to do anything now. (Teacher L)

The examinations and whether or not to include environmental education pose a dilemma.

In Singapore, if it is non-examinable, nothing works . . Nothing works unless you award marks, award money. It is sad to say but it works that way. I think the whole system is so practical. (Teacher W)

This pragmatism was taken up by another.

Once it [referring to environmental education] is non-examinable, Singaporeans don't encourage children to take it up ... (Teacher L)

But

What we worry is that once environmental education is made an examinable subject, students just learn it to pass the exam. After the exam, they forget all about it and [we] will still have environmental problems. That's why we make it as extra-curricular activities. (Ministry of Environment Official T)

Since these interviews the Government of Singapore has proposed a move to increase the flexibility within the public examination system. It is suggested that project work be introduced and more open-ended questions be included in examinations in a move towards multiple modes of assessment. However, it remains to be seen what effects these will have on environmental education.

Teachers gave the impression of that they felt controlled by the system. The feeling of helplessness and frustration was expressed.

We do what inspectors ask us to do. (Teacher W, a Head of Department)

They [referring to the government officials] told us what to do and we do what we're told... They made the decision and the selection. (Teacher U) 
Teachers recognise that these people come from their ranks but they imply that once people become a part of the inspectorate there is a barrier and views of the curriculum from the classroom are not carried through, or carried through with any force, to where decisions are made. A feeling of a lack of involvement in curriculum development was expressed.

We did not really have the chance to talk about it [the environmental education curriculum]. (Teacher D)

Teachers seemed to see themselves as just implementers in a top-down bureaucratic educational system. This is not to say that teachers are not consulted. One (Teacher J) described how teacher feedback had argued that one part of the curriculum was dull and changes were made. However, teachers did not personally identify or feel ownership of what was being taught.

Some teachers who were environmentally committed were frustrated by what they saw as half-hearted misdirected attempts at environmental education.

The Government encourages recycling, but there is nobody encouraging people to collect newspaper ... People will be fined if they throw things not supposed to be in the bin. There is a lack of education. You [referring to the teachers in Singapore schools] don't educate the individual, you just cuff the problem, so you have no problem ... Here we encourage them to do something but there is no impetus from outside... If you say something, it later fizzles out. The whole population thinks that the Government says something but there is nothing done. The government does not put $100 \%$ effort into it ... City cleanliness [campaigns] in Singapore is not environmental education in itself. It is something you have to otherwise you will be punished. (Teacher Z)

It [referring to city cleanliness] is for image. (Teacher C)

What the environmental and educational authorities define as environmental education is not always what teachers, a minority admittedly, perceive it should be, and they are critical that environmental education stops short at government propaganda rather than expanding and developing more ecocentric beliefs. There is the view that the Singapore education system (expressed as the Government) does not take environmental education seriously.

In Singapore, I don't think it is taken seriously ... they should slot in the timetable a period for environmental study ... They have made a start . . . [but] I think not enough is done. They [referring to the authorities] should set programmes, set syllabuses. That means, make it compulsory. (Teacher W)

Overall, there are mixed messages coming from schools. From a minority of committed environmental educators there is frustration at what is being attempted both in quantitative and qualitative terms. However, from the majority there is a resigned acceptance of the status quo. Barriers are seen as too great. 


\section{The role of government in the development of environmental education}

Environmental education is a key direction of the 'Green Plan'. Cultivating knowledge of the scientific and social significance of the environment is the first step in the founding of an environmentally friendly society ... To build an environmentally proactive society new directions were necessary, (Ministry of Environment, 1993: 13).

The Government, through the Ministry of Environment, thus saw, and continues to see, its role as to lead and set directions where environmental education should go. This, of course was, and still is to a large extent, common to many aspects of Singaporean life. A poster in the MRT railway system perhaps summed this up by declaring the Confucian belief that:

When we see people of virtue, we want to imitate them;

When we see bad people, we reflect on ourselves.

The message, put out by the government information service, is to follow the lead of the virtuous and by implication, given Confucian reverence for authority, the Government. The position is strongly paternalistic. Social control, it is felt, encourages social stability, economic development and the general good of the people and the country. It is thus not surprising that development of environmental education is largely top down and bureaucratic.

An official (T) from the Ministry of Environment commented:

Our ministry is undertaking the main work. Because there is more [in the environmental education curriculum] on subject matter, environmental education is the work of our ministry rather than the MOE [the Ministry of Education]. But for certain parts of environmental education like nature conservation, other departments like the National Parks Board also come into the picture ... But if we are concerned with environmental public health, pollution and waste recycling, our department does most of the work.

There is no mention of NGOs or community action groups and the same is true in aspects dealt with by the education agencies. He continued:

The Curriculum Development Institute of Singapore, in short form the CDIS, is a division of the Ministry of Education. It helped the MOE to compile the book for teaching students. They rely on us [the Ministry of Environment] very often. They want to incorporate our articles into the curriculum ... We worked very closely. We invited staff from the MOE to join us so that they are aware of what we are doing.

The Ministry of Environment gives the impression of retaining overall control of the direction being taken with ideas being operationalised through collaborative work with the MOE. There is the view of the MOE seemingly designing a curriculum to a tune played by the Ministry of Environment.

Whatever is the actual relationship between arms of the Government, the clear perception is one of top-down control and strong leadership from above. This was clearly felt by teachers.

The syllabus is written by the MOE and they have a syllabus committee 
consisting of ministry [of Education] staff and selected teachers [as well as presumably MOE staff]. That is how they go about drafting the syllabus. (Teacher W)

A teacher of Chinese, in a group interview, gave the impression of teachers 'being controlled by the system' and in desperation said:

They [referring to government officials] told us what to do and we do what we were told ... They made the decisions and the selection [of teaching content]. (Teacher T)

Government control raises political issues of image and identity. There is a desire to adopt global initiatives but with Singaporean characteristics. The Ministry of Environment noted:

The Government decided not to adopt a 'model country' in environmental education. It is difficult to compare our [meaning the Singaporean] level of environmental education with that of any country, as there are no clearly defined parameters for comparison. Instead, we adopted the present level of environmental education as a basis from which targets and improvements would be suggested. (Ministry of Environment, 1993: 3)

The Singaporean Government sees its solution to the form environmental education should take as necessarily being unique. Local standards would be met which would be consistent with the views of government and its, what some see as draconian, actions could and should be adopted. The Singaporean Government, particularly a decade or so ago, was wary of socially destabilising movements from the West (Clammer, 1985). It, as we have noted already, had more pragmatic aims for its environmental education programmes than in some Western countries that might offer themselves as models.

Satisfying domestic needs was and still is a crucial element in setting directions. This, however, should not be seen as implying a totally myopic view. At the operationalising level in the classroom, for instance, an activity approach based on US references was adopted as it matched the local needs.

We are quite influenced by the American system. In the American books, ecology is also very big... The books from America are well packaged, clear [and] with activities. That is the way we want our science projects to be [and our] teaching to be [namely] project-based inquiry approach. (Teacher J)

If ideas from outside of Singapore ('foreign ideas') are suitable in the 'pursuit of excellence' as it is conceptualised in Singapore, they are adopted (Savage, 1994). The needs as perceived by the Government, take priority. Whilst it would be incorrect to claim that there is no disagreement, what is suggested by the administration is often accepted as right for Singapore. People are resigned to compliance.

We have no problem [with what the Government does], we have no choice either. We have to follow. (Teacher J) 
There is also a sense of pride in Singapore that supports and abets compliance. Two teachers, one who was incidentally also a former government official, commented:

The Singaporean Government has actually expended effort to cater for future needs. I think our Government is farsighted and very good. (Teacher P)

Some people criticise that our Government is strict and tough but I myself feel very comfortable about it. (Teacher T)

There were, thus, teachers who viewed the Government's centralist, interventionist position in a positive light but these formed a minority. Most just accepted their position and the dominant position of the Government.

The question arises as to how serious the Singapore Government is in developing environmental education. The Singapore Government, as with any government, faces forces that are at times conflicting. For largely, but not solely, economic reasons within Singapore, it seeks environmental improvement and wants to encourage initiatives in the city-state that can enhance its prosperity. At times, environmental protection and economic development work hand in hand, but at other times these conflict and development puts environmental sustainability at risk. Singapore realises that it has a role in the global world and identifies with many of the global environmental imperatives. On the other hand, it is concerned when either global ideas about the environment or initiatives by individuals run counter to its own environmental plan or its desire to maintain prosperity and social stability. In this its stance, which is manageralist and accommodating, is similar to many other countries. It is often left attempting in a balancing act that leans towards environmental conservatism rather than radicalism and transformation.

\section{Conclusion}

The three themes identified within the interview data lead us to suggest three important context variables: the environment, the school system and the Government. The findings are summarised in Figure 1. Perceptions of the environment and environmental issues reflect a tension between wildlife interests concerned with habitat loss and pollution with ecological and Gaian view points, on the one hand, and on the other, environmental health interests concerned with providing healthy surroundings for the building of the economy and the nation which is underpinned by utilitarian concepts of environment and technological solutions. This dilemma exists both between government departments and NGOs and between more conservative and more progressive socially critical teachers, where it is most obvious, but also within individual government officials and teachers.

Tensions also are apparent in the school system. There is commitment to environmental education in the school and, at times, a passionate commitment among a significant minority of teachers and curriculum developers. Balancing the various, often conflicting, demands on classrooms in Singapore presents a constraint on infusing an environmental dimension and, one suspects in the case of conservative teachers, a ready excuse for not doing so. Indeed, a socially 


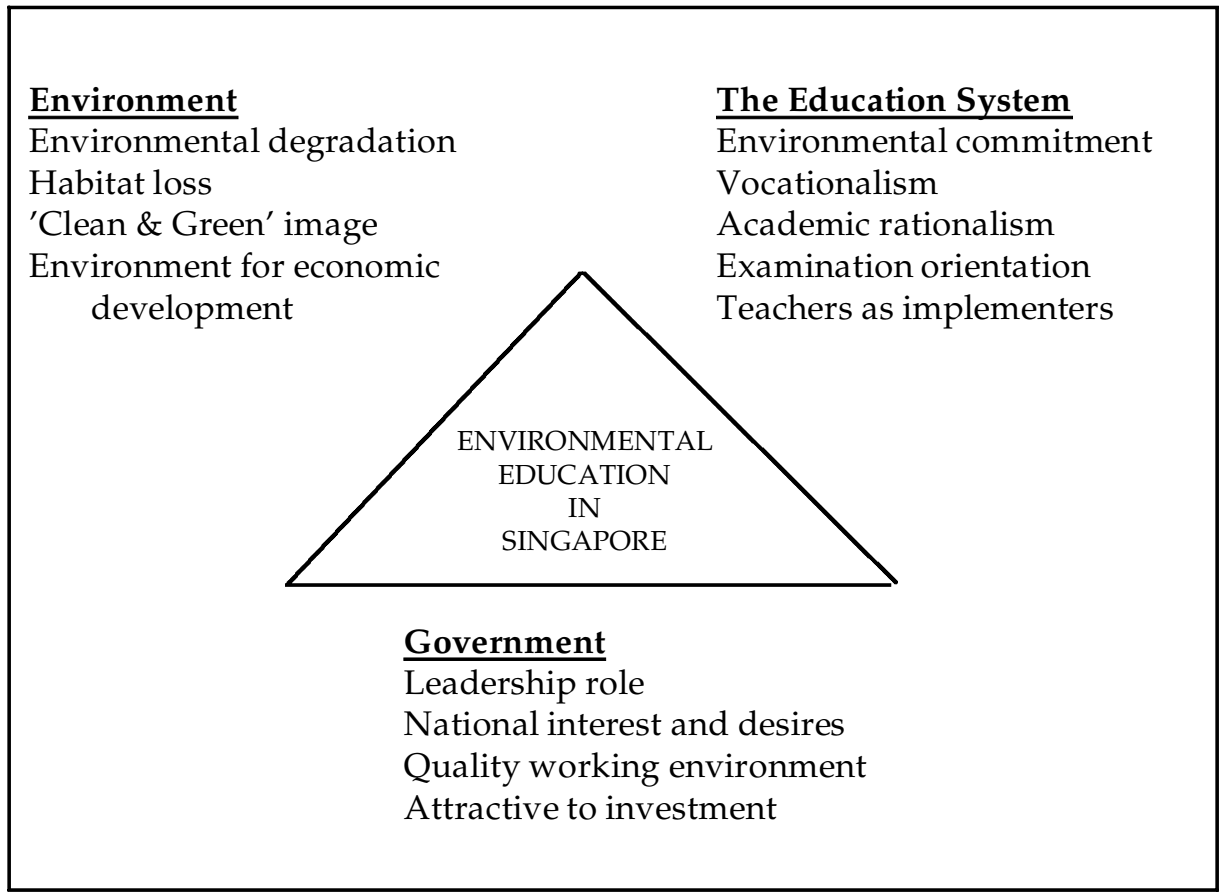

Figure 1 Key context variables

critical environmental education is inconsistent with the premises and precepts of much of the mainstream core curriculum. External examinations and accountability measures hold teachers to curricula that are academic rationalist rather than socially critical and emancipatory in character. Whilst the Singapore Government is attempting to reduce the negative backwash effects on the school curriculum with the encouragement of the sort of critical thinking also needed in environmental education, demands from the economy highlight priorities of a technical and knowledge-oriented kind. Most of all teachers do feel themselves expected or empowered to bring about change; their perceived role is often compliance with instructions and implementation of prescribed content.

Pervading both views of the environment and of environmental education in schools is the controlling, proactive hand of government, which is reminiscent of arguments in Apple $(1982,1996)$ on cultural politics and education. The Singapore Government adopts a high profile, strong yet paternalistic leadership style in its laudable desire to promote Singapore as a centre of excellence and providea high standard of living for its people. Strong government (and compliance by the populous) was perceived as the only way in the last three or four decades to achieve these aims. Sustaining the environment is a key plank in creating a 'better' Singapore. However, this was in the sense that the environment could be successfully managed so that it did not constrain the economic development that would be at the heart of developing social cohesiveness and national identity. In this the Singapore Government has been remarkably successful, but in doing so it has largely taken ethical issues with regard to the environment out of the hands 
of classrooms, values positions being predefined and prescribed. Curriculum planning in general is centralised within a rationalist model of planning; notions of a 'process model', contextualised within the actual environmental issues facing schoolchildren and their development as both Singaporean and global citizens that would empower teachers to decide what and how to teach, is absent in any depth. Teachers feel professionally that they must conform to the Government's decisions on the direction to take even if they personally do not fully agree with the curricula they have to teach. This is, of course, not unknown in other education systems and is, for example, well articulated by Elliot (1998) in the case of environmental education in the UK, although we have no evidence to suggest that the convolutions he identified are present in Singapore. The Singapore Government needs strong control over education to bring about the excellence it seeks as a prerequisite for economic growth. However, it is just this control that closes down the space for teachers to develop environmental education much beyond transmission. Project work is being encouraged in secondary schools related to, but also confined within, the limits of the Ministry of Environment programmes described in the beginning of the paper. These create what Elliot has described in the UK as 'politically symbolic acts which publicly signify concern for the environment, rather than with the construction of effective and educationally worthwhile pedagogic practices for environmental education' (Elliot, 1998:174). One is thus left with the conclusion that the Singapore Government subscribes to environmental sustainability but also, and as a higher priority, the economic, social and political sustainability of Singapore as a national entity. The Government's concern is with achieving national outcomes rather than a concern with both outcomes of environmental education and process by which it brought about. At times national economic, social and political goals coincide with broader goals for environment; at other times there is tension and this is exposed in directions taken by environmental education in the formal school sector.

\section{Correspondence}

Any correspondence should be directed to Philip Stimpson, Faculty of Education, The University of Hong Kong, Hong Kong (hraspgs@hkucc.hku.hk).

\section{References}

Apple, M.W. (1982) Cultural and Economic Reproduction in Education: Essays on Class, Ideology and the State. London: Routledge.

Apple, M.W. (1996) Cultural Politics and Education. Buckingham: Open University Press. Boh, B. (1991) Environmental Education in Asian Countries. Washington: World Bank.

Clammer, J. (1985) Singapore: Ideology, Society, Culture. Singapore: Chapman.

Curriculum Planning Division (1993) Science Syllabus (Lower Secondary). Singapore: Ministry of Education.

Elliot, J. (1998) The Curriculum Experiment: Meeting the Challenge of Social Change. Buckingham: Open University Press.

Glaser, B. and Strauss, A.L. (1968) The Discovery Grounded Theory: Strategies for Qualitative Research. Chicago: Aldine.

Goodson, I. (1994) Subjects for study: Towards a social history of curriculum. In I. Goodson and S. Ball (eds) Defining the Curriculum: Histories and Ethnographies. London: Falmer. 
Kellert, S.R. (1997) The Value of Life: Biological Diversity and Human Society. Washington, DC: Island Press.

Koh, T. (1990) Forward. In Master Plan for the Conservation of Nature. Singapore: Malaysian Nature Society.

Koh, T. (1993) Preface. In Singapore Green Plan. Singapore: Singapore Government.

Kong, L. (1993) Urban constraints, political imperatives: Environmental 'design' in Singapore. Paper presented at the symposium on Environment and Culture, Siam Society, Bangkok.

Lim, L.Y. (1992) Environmental management in Singapore. Paper presented at the International Conference on Environmental Management, Centre for Urban Planning and Environmental Management, University of Hong Kong, Hong Kong.

Malayan Nature Society (1990) Master Plan for the Conservation of Nature. Singapore: Malayan Nature Society.

Marsh, C. and Willis, G. (1995) Curriculum: Alternative Approaches, Ongoing Issues. Englewood Cliffs, NJ: Prentice-Hall.

Ministry of Education (2000a) Desired outcomes of education. On WWW at http:// www1.moe.edu.sg/bri.edusys.htm.

Ministry of Education (2000b) Secondary education. On WWW at http:// www1.moe.edu.sg/secondary.htm.

Ministry of Environment (1993) Singapore Green Plan. Singapore: Ministry of Environment.

Print, M. (1993) Curriculum Development and Design. Sydney: Allen \& Unwin.

Reynolds, D. and Skilbeck, M. (1976) Culture and the Classroom. London: Open Books.

Robertson, C.L. and Krugly-Smolska, E. (1997) Gaps between advocated practices and teaching realities in environmental education. Environmental Education Research 3 (3), 311.

Savage, V.R. (1994)Human-environment relations, Singapore's environmental ideology. In B.K. Choon, A. Pakir and C.K. Tong (eds) Imaging Singapore. Singapore: Times Academic Press.

Savage, V.R. and Lau, S. (1993) Green issues: Official policies and student awareness. In C. Briffett and LL Sim (eds) Environmental Issues in Development and Conservation. Singapore: School of Building and Estate Management, National University of Singapore.

UNESCO (1978) International Conference on Environmental Education: Tibilisi (USSR), 14-16 October, 1977 Final Report. Paris: UNESCO.

UNESCO (1990) Singapore: Report of Regional Training Course for Science Teachers and Supervisors on Environmental Education in the ASEAN Region. Bangkok: UNESCO Principal Regional Office for Asia and the Pacific.

UNESCO-UNEP (1988) International Strategy for Action in the Field of Environmental Education and Training for the 1990s. Paris: UNESCO and Nairobi: UNEP. 